\title{
Structural effects on compressive strength enhancement of concrete-like materials in a split Hopkinson pressure bar test
}

DOI:

10.1016/j.jimpeng.2017.08.003

\section{Document Version}

Accepted author manuscript

Link to publication record in Manchester Research Explorer

Citation for published version (APA):

Flores-Johnson, E. A., \& Li, Q. M. (2017). Structural effects on compressive strength enhancement of concrete-like materials in a split Hopkinson pressure bar test. International Journal of Impact Engineering, 109, 408-418. https://doi.org/10.1016/j.jijimpeng.2017.08.003

\section{Published in:}

International Journal of Impact Engineering

\section{Citing this paper}

Please note that where the full-text provided on Manchester Research Explorer is the Author Accepted Manuscript or Proof version this may differ from the final Published version. If citing, it is advised that you check and use the publisher's definitive version.

\section{General rights}

Copyright and moral rights for the publications made accessible in the Research Explorer are retained by the authors and/or other copyright owners and it is a condition of accessing publications that users recognise and abide by the legal requirements associated with these rights.

\section{Takedown policy}

If you believe that this document breaches copyright please refer to the University of Manchester's Takedown Procedures [http://man.ac.uk/04Y6Bo] or contact uml.scholarlycommunications@manchester.ac.uk providing relevant details, so we can investigate your claim.

\section{OPEN ACCESS}




\section{Structural effects on compressive strength enhancement of concrete-like materials} in a split Hopkinson pressure bar test

${ }^{a}$ CONACYT - Unidad de Materiales, Centro de Investigación Científica de Yucatán, Calle 43, No. 130

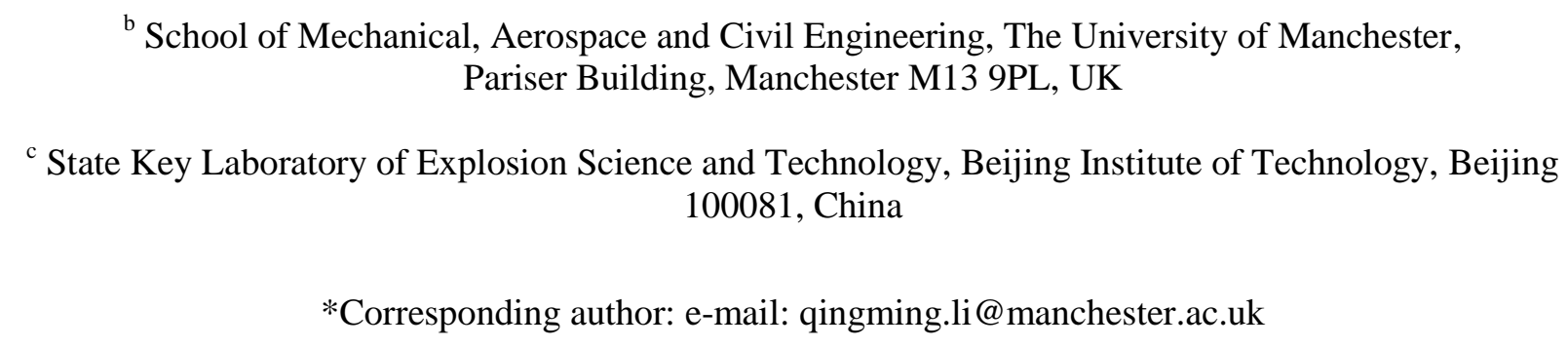

*Corresponding author: e-mail: qingming.li@manchester.ac.uk

Abstract: Many researches have confirmed that the dynamic increase factor (DIF) of concretelike materials in compression measured by split Hopkinson pressure bar (SHPB) includes considerable structural effects, which do not belong to strain-rate effect. It has been found that the factors responsible for structural effects include material parameters (i.e. hydrostatic dependence, dilation parameter), specimen geometry (i.e. diameter), end interface friction and material inertia. However, their intrinsic relations have never been fully clarified. Based on two well-established material models (extended Drucker-Prager model in Abaqus and the Concrete Damage Model Release III in LS-DYNA), this paper uses numerical SHPB tests to investigate the interactive relations among these structural factors. It was found that the lateral confinement in a SHPB specimen is responsible for all structural effects in a SHPB test of concrete-like material. Two independent mechanisms can produce the lateral confinement, i.e. (i) friction on the interface of SHPB specimen and pressure bars, which prevents the expansion of the SHPB specimen during compression, and (ii) lateral inertia in SHPB specimen, which generates reactive radial confinement stress. Dilation can further enhance DIF, but it has to interact with either or both mechanisms. The ways that various structural factors contribute to structural effects through these mechanisms are clarified.

Keywords: Split Hopkinson pressure bar; structural effects; concrete-like materials; dynamic increase factor; finite-element modelling. 
Further studies [1-4] support the quantitative findings in Li and Meng [5], which showed that the dynamic uniaxial compressive strength of concrete-like materials measured by split Hopkinson pressure bar (SHPB) includes considerable pseudo strain-rate effects (or structural effects), introduced by various structural factors (e.g. end interface friction, specimen geometry, lateral inertia etc.). Clearly, the apparent strain-rate enhancement of material strength due to structural effects cannot be considered as a genuine strain-rate effect. Numerical split Hopkinson pressure bar (NSHPB) tests [6] based on the "reconstitution method" [7] have been used to study the structural effects $[1-4,6]$. In a NSHPB test, a phenomenological strain-rateindependent strength model is employed for the SHPB sample material. Therefore, the apparent strain-rate effect on the dynamic compressive strength from a NSHPB test represents the structural effect.

It has been shown $[1-4,6]$ that when the compressive strength of a material is sensitive to hydrostatic pressure, the lateral confinement developed in the SHPB sample can enhance its axial compressive strength. Two conditions are necessary for the existence of structural effect in a SHPB test, i.e. (i) the compressive strength of the tested material is hydrostatic sensitive, and (ii) lateral confinement can be developed in the SHPB sample. Since the strength of concretelike materials is much more sensitive to hydrostatic pressure (e.g. Drucker-Prager model) than that of metallic materials (e.g. von-Mises model), structural effects in a SHPB test are normally associated with concrete-like materials rather than metallic materials.

Structural effects due to end interface friction, specimen diameter and lateral inertia have been studied before [1-4, 6, 8-10]; however, shear dilation was either ignored or considered implicitly. A recent numerical study [11] investigated the effect of the shear dilation on the compressive strength of concrete in a SHPB test and found that the dynamic increase factor (DIF) of concrete obtained from SHPB tests increases with material dilation. Dilation (or dilatancy) of concrete-like materials refers to the volume increase resulting from the formation and growth of micro-cracks around aggregate in shear and compression $[12,13]$, which can directly contribute to the increase of lateral confinement, and thus, the increase of measured compressive strength in a SHPB test. When shear dilation has been included in the strength model of a material, its apparent strain-rate effect on the compressive strength in a SHPB test should be considered partly as a structural effect. However, the way that dilation contributes to the increase of compressive strength may be different from other structural factors. Furthermore, it is still unclear how individual structural factors interact and produce the overall structural effect. Therefore, it is necessary to perform further studies to clarify the above issues.

In this paper, we perform finite-element (FE) simulations using two well-known concrete constitutive material models that take into account material dilation, i.e. the extended Drucker- 
72 Prager model (D-P model) in Abaqus and the Concrete Damage Model Release III (Material

73 072R3 or K\&C model) in LS-DYNA, to study the interactions among structural factors and 74 their influence on the apparent compressive strength measured in a SHPB test. The mechanisms 75 responsible for the DIF enhancement through material dilation are discussed to generalise the conclusions from numerical results. FE models are described in Section 2. Numerical results are presented in Section 3 followed by a discussion about the interactions among structural factors and their influence on DIF in Section 4. Conclusion remarks are presented in Section 5.

\section{Numerical simulations of SHPB tests}

The FE simulations of SHPB tests in this work were performed with a similar setup as that presented by Grote et al. [14]. The geometrical details of the specimen and the incident and transmission bars are given in Table 1. The numerical simulations were performed using the commercial (FE) software Abaqus/Explicit [15] and LS-DYNA [16]. To reduce computational costs, a representative quarter-model was constructed using 8-node brick elements with reduced integration (Fig. 1). The elements of the specimen and the pressure bars around the specimenbar interfaces (Fig. 1) have an average size of $0.2 \times 0.2 \times 0.2 \mathrm{~mm}^{3}$. The total numbers of elements are 17250 for the SHPB specimen and 43365 for each pressure bar, respectively. A mesh sensitivity analysis showed that smaller element size did not further change the numerical results. A transition mesh was used in the radial direction of the specimen and in the axial direction of the bars to reduce the total number of elements (Fig. 1).

The input and output bars of the SHPB were modelled using an isotropic elastic material model with input parameters shown in Table 1. The specimen was modelled in Abaqus using the D-P model with linear pressure-dependence and material parameters shown in Table 1 as well as quasi-static hardening-softening input curve shown in Fig. 2, which has an initial yield stress of $18 \mathrm{MPa}$ and peak unconfined uniaxial compressive strength $f_{c}^{\prime}$ of $40 \mathrm{MPa}$. For LS-DYNA numerical simulations, the Material 072R3 was employed using the parameter generation capability, which is based only on the unconfined compressive strength $\left(f_{c}^{\prime}=40 \mathrm{MPa}\right)$ [17]. An overview of the dilation parameters in each model is given in Section 2.1. A full description of the constitutive relations for both models is given in the Appendix.

Table 1 Geometrical details, material properties and material model parameters

\begin{tabular}{|l|l|l|}
\hline Material properties and geometrical details & Specimen [14] & Input/output bar \\
\hline Density $\rho\left(\mathrm{kg} / \mathrm{m}^{3}\right)$ & 2000 & 7800 \\
\hline Young's modulus $E(\mathrm{GPa})$ & 30 & 210 \\
\hline Poisson's ratio $v$ & 0.19 & 0.3 \\
\hline Diameter $D(\mathrm{~mm})$ & 12,20 & 21 \\
\hline
\end{tabular}




\begin{tabular}{|l|l|l|}
\hline Length $L(\mathrm{~mm})$ & 6 & 1000 \\
\hline Material model parameters & Specimen & \\
\hline $\begin{array}{l}\text { Unconfined uniaxial compressive strength } f_{c}^{\prime} \\
(\mathrm{MPa})(\mathrm{D}-\mathrm{P} \text { and Material 072R3 models) }\end{array}$ & 40 & - \\
\hline & $0,30,50$ & \\
\hline Friction angle $\beta\left(^{\circ}\right)(\mathrm{D}-\mathrm{P}$ model) & $0,30,50$ & - \\
\hline Dilation angle $\psi\left(^{\circ}\right)(\mathrm{D}-\mathrm{P}$ model) & 1 & - \\
\hline Parameter $K(\mathrm{D}-\mathrm{P}$ model) & $0,0.5,1$ & - \\
\hline Dilation parameter $\omega$ (Material 072R3) & & \\
\hline
\end{tabular}

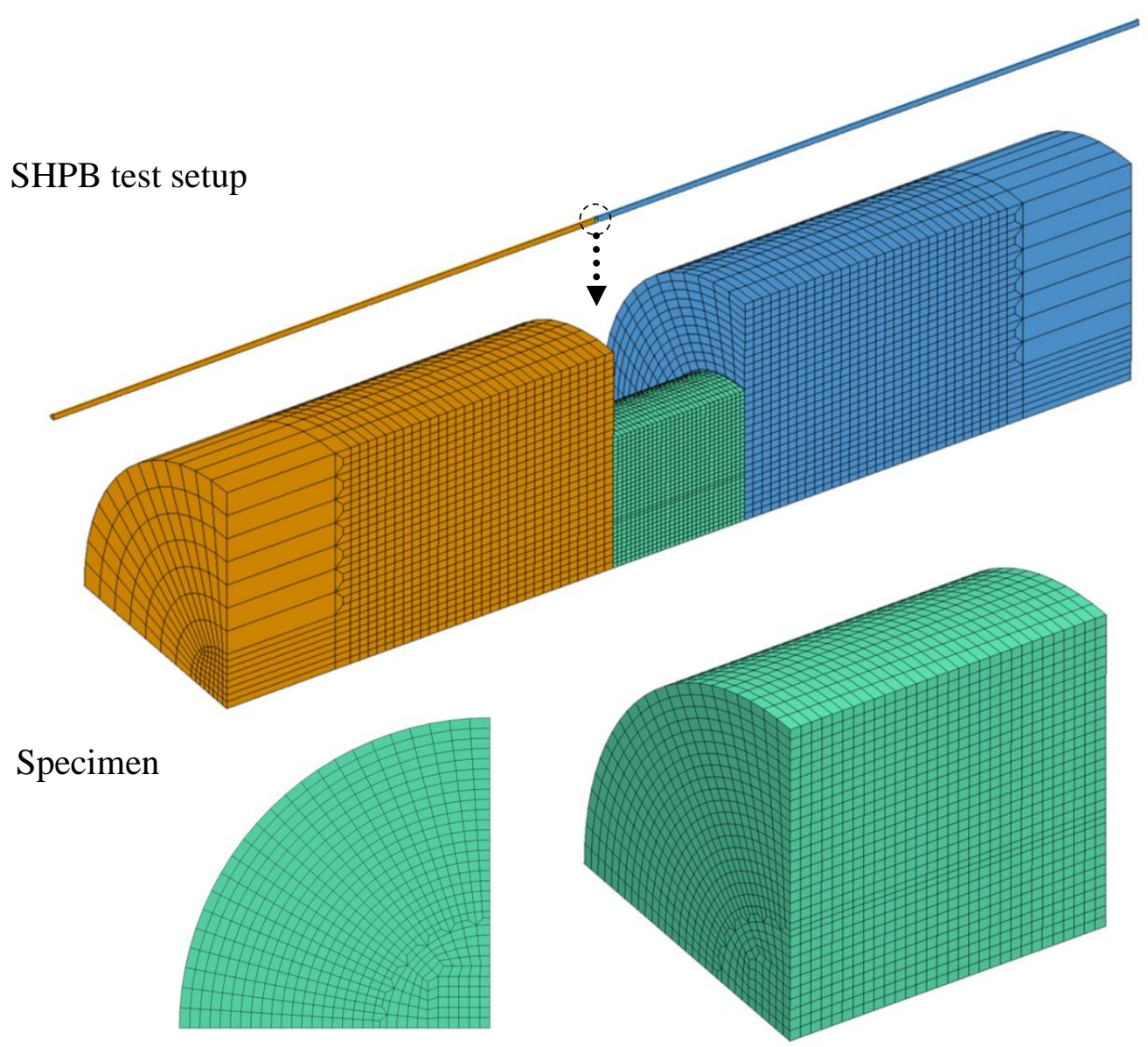




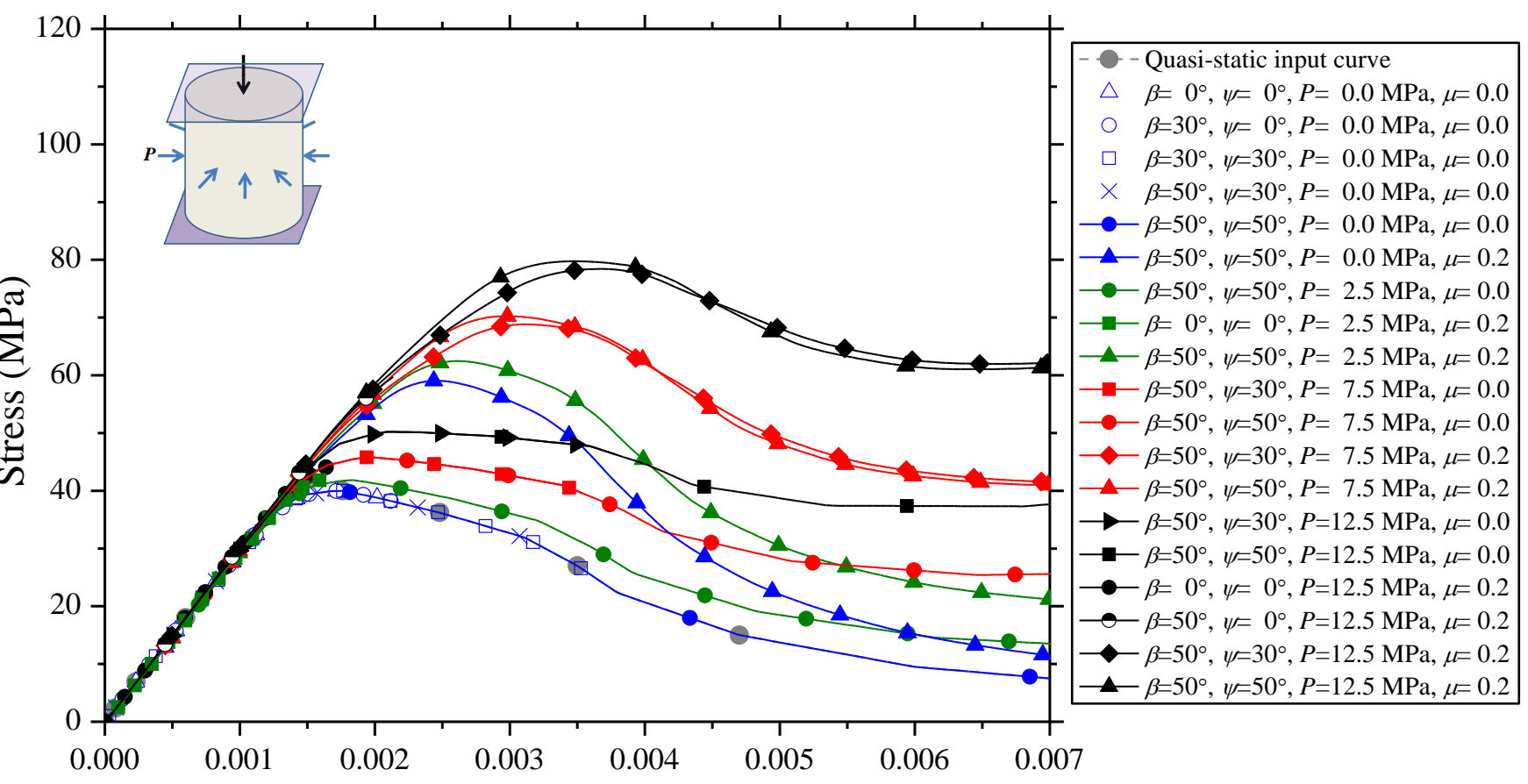

\section{Strain}

Fig. 2 Stress-strain curves for different input parameters and lateral confinements at quasi-static loading $\left(\dot{\varepsilon}=8 \times 10^{-2}\right.$

\subsection{Shear dilation parameters in D-P and Material 072R3 models}

A full description of the constitutive relations for the Extended Drucker-Prager (D-P) model in Abaqus and the Concrete Damage Model Release III (Material 072R3) in LS-DYNA can be found in the Appendix.

In the (D-P) model, the plastic flow potential $G$ is defined as [18],

where $t$ is the deviatoric stress measure, $p$ is the equivalent pressure stress and $\psi$ is the dilation material dilates.

156 In the Material 072R3, the plastic flow potential $g$ is defined as [19], 
where $F$ is a loading surface depending on the stress invariants $I_{1}, J_{2}$ and $J_{3}$ (Appendix).

160 Dilatancy is taken into account via the parameter $\omega$, which defines the amount of dilation that can occur in the material. When $\omega=0$, there is no volume change during plastic flow and when $\omega>0$ the material dilates.

163 By comparing the full description of both models in the Appendix, it is unlikely to establish a direct relationship between D-P model and Material 072R3 model due to the difference between their respective plastic potential functions and strength surfaces. Consequently, the dilation parameters in these two models have no general relationship. However, dilation parameters $\omega$ in Material 072R3 model has a similar function to that of the dilation angle $(\tan \psi)$ in the D-P model under certain conditions. For example, when comparing the plastic flow potentials for the D-P model (Eq.(1)) and Material 072R3 (Eq.(2)), it can be seen that $\omega$ in the latter model plays a similar role to that of the dilation angle $(\tan \psi)$ in the D-P model when $K=1$ (where $K$ is the ratio of the yield stress in triaxial tension to the yield stress in triaxial compression in D-P model, see Appendix) which leads to $t=q / 2=\left(\sqrt{3 J_{2}}\right) / 2$ (where $q$ is the Mises equivalent stress). In this case, both material models can be reduced to the same non-associative flow rule (i.e. $g=2 \mathrm{G}=$ $\sqrt{3 J_{2}}$ ) when $\omega=\tan \psi=0$, and to the fully associative flow rule when $\omega=1$ and $\tan \psi=\tan \beta$ (where $\beta$ is the friction angle in D-P model). This implies that zero value of dilation parameters in both models is associated with plastic incompressibility (or zero plastic dilation).

For concrete, a partial associative flow rule should be used according to experimental observation. In general, the variation range of dilation parameters in Material 072R3 and the DP model are $0<\omega<1$ and $0<\tan \psi<3$, respectively, which control the amount of associativity, and therefore, the change in volume (dilation) during plastic flow.

\subsection{Numerical analyses of SHPB test}

183 A parametric study of the effects of structural factors (i.e. the friction angle, dilation, friction coefficient, specimen diameter, inertia and Poisson's ratio) on the DIF of concrete at strain-rates

185 in the range of $10^{1}-10^{3} \mathrm{~s}^{-1}$ is performed. For the numerical simulations performed in 186 Abaqus/Explicit, three friction angle values $\beta=\left(0^{\circ}, 30^{\circ}, 50^{\circ}\right)$, three dilation angle values $\psi=$ $187\left(0^{\circ}, 30^{\circ}, 50^{\circ}\right)$ and three friction coefficient values $\mu=(0,0.1,0.2)$ are used. The effect of inertia 188 is studied using reduced values of density $\rho\left(20\right.$ and $\left.200 \mathrm{~kg} / \mathrm{m}^{3}\right)$. A larger specimen diameter of $18920 \mathrm{~mm}$ and zero Poisson's ratio are also investigated. For the numerical simulations performed 190 in LS-DYNA, three dilation parameter values $\omega=(0,0.5,1)$ and two friction coefficient values $\mu=(0,0.2)$ are used. 
To achieve different strain-rates, trapezoidal stress pulses with different rising time and intensity are applied to the end of the incident bar. The rising time varies from 70 to $100 \mu \mathrm{s}$ while the duration and unloading times are fixed to $20 \mu$ s as they do not have an effect on the strain-rate because the specimen reached peak strength during the loading time. The intensity of the pulse varies from 50 to $1000 \mathrm{MPa}$.

Strain-rate effect is ignored in both material models in order to study structural effects. To measure the axial stress and strain-rate in the specimen in numerical simulations, several methods were compared: (i) the formulae described in [20, 21] (Eq.(3) and Eq.(4)), which use the stresses and velocities at the specimen interfaces to obtain the time histories of the average engineering stress $\sigma(t)$ and average strain-rate $\dot{\varepsilon}(t)$ over the specimen, i.e.,

where $\left(\sigma_{I}(t), V_{I}(t)\right)$ and $\left(\sigma_{T}(t), V_{T}(t)\right)$ are the stress and velocity time histories at the interfaces between the incident bar and the specimen, and between the transmitter bar and the specimen, respectively, and the constant $L_{S}$ is the specimen length; (ii) an average of the direct measure of axial stress and axial strain-rate in all the elements of the specimen; and (iii) an average of the direct measure of the axial stress and axial strain-rate in a layer of elements located at the transverse mid-plane in the specimen. It was found that the maximum relative

213 differences for the results obtained with the three methods are within $2 \%$. Thus, we used the 214 latter method to save data processing time.

215 It is known that if the peak stress in the specimen is reached before the stress equilibrium is 216 achieved, the test may not be valid. The dynamic stress equilibrium was verified using the parameter $R(t)$ defined as [20,21],

It is generally accepted that if the stress difference across the SHPB specimen is no more than $5 \%$ of the average stress, i.e., $R(t) \leq 0.05$, the stress equilibrium condition is satisfied [22].

223 Numerical simulations performed in Abaqus/Explicit (Fig. 3) show the variation of $R(t)$ with the normalised time $t / t_{0}$ where $t_{0}=L_{S} / c_{S}$ is the transit time duration for the longitudinal incident pulse 
travelling one specimen length. The specimen length $L_{S}$ in Fig. 3 is $6 \mathrm{~mm}$ and the elastic wave speed is $3105 \mathrm{~m} / \mathrm{s}\left(t_{0}=1.93 \mu \mathrm{s}\right)$; the stress equilibrium is achieved after 6 times of stress wave reflections in the SHPB specimen before the peak strength is reached. Therefore, the measured strength can be considered valid [20]. It can also be seen in Fig. 3 that a large oscillation occurs

229 after the peak stress is reached. This is due to the loss of stress equilibrium when the specimen is 230 largely damaged. However, these large oscillations do not affect the numerical results in this 231 investigation since only the peak strength is of interest. It can also be seen in Fig. 3 that for $232 \dot{\varepsilon}(t)>640 \mathrm{~s}^{-1}$ the stress equilibrium is not achieved before the peak strength is reached and 233 therefore the simulation may not be valid. For this reason, the results for $\log (\dot{\varepsilon})>2.8$ will not be 234 used in this study.

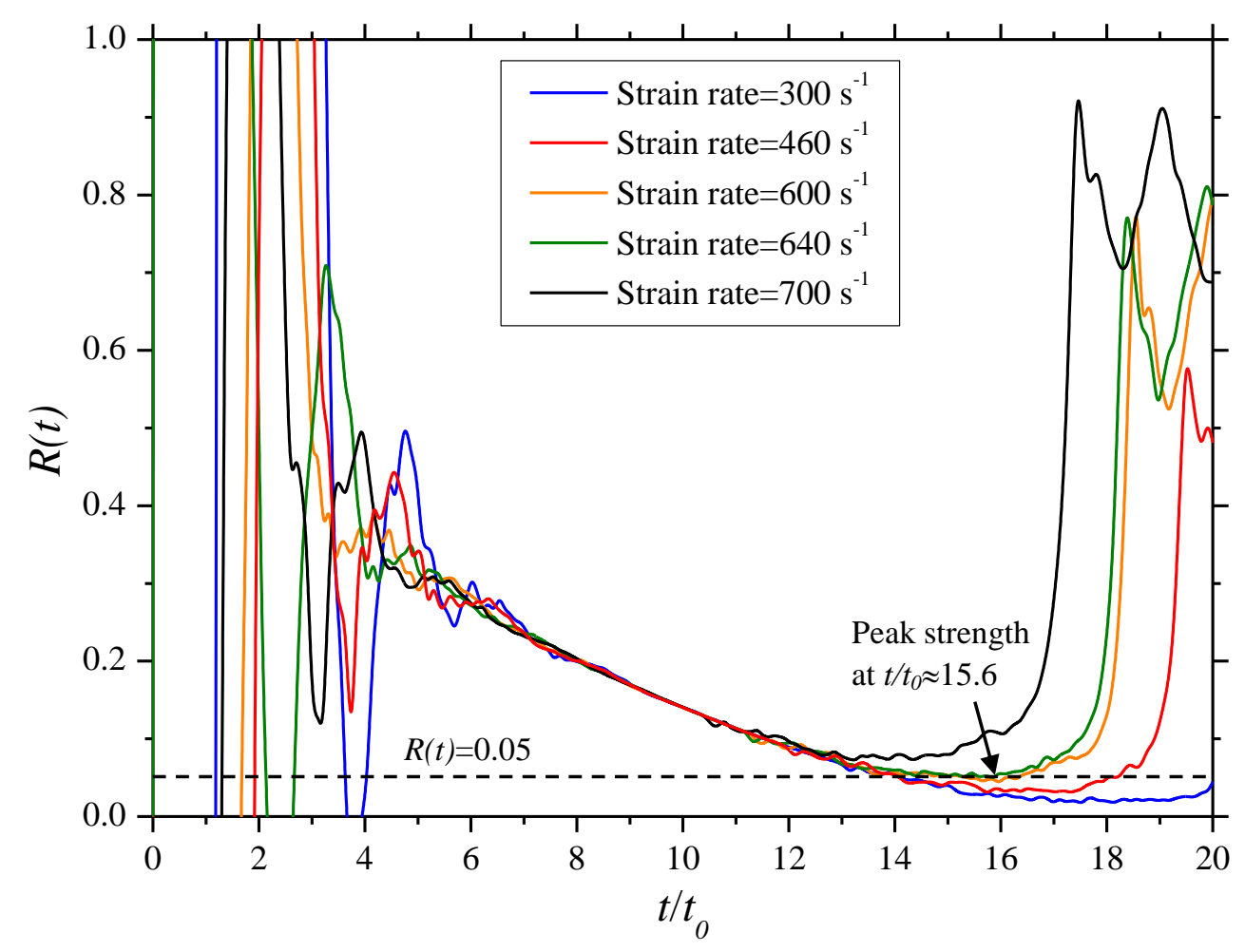

Fig. 3 Dynamic stress equilibrium $R(t)$ versus normalised time $t / t_{0}$ for a 12 -mm mortar specimen subjected to different strain-rates in SHPB test.

\section{Numerical results and discussion}

In this section, the effects of dilation and several other structural factors such as coefficient of 258 Numerical simulations are performed using D-P model in Abaqus and Material 072R3 model in 


\subsection{Numerical simulations using D-P model in Abaqus}

262 Figure 2 shows quasi-static compression stress-strain curves performed at low strain-rate $263\left(\dot{\varepsilon}=8 \times 10^{-2} \mathrm{~s}^{-1}\right)$ with different radial confinement pressure $P$, friction coefficient and material 264 parameters, using D-P model in Abaqus. It is noted that $\dot{\varepsilon}=8 \times 10^{-2} \mathrm{~s}^{-1}$ is used for quasi-static 265 simulation in order to save simulation time because the results at this strain-rate are almost 266 identical to the results obtained at strain-rate of $\dot{\varepsilon}=10^{-3} \mathrm{~s}^{-1}$. It can be seen in Fig. 2 that without 267 radial confinement pressure and interface friction, no enhancement of the compressive stress268 strain curves is observed even though the material friction angle is not zero. This implies that 269 under quasi-static loading condition, the uniaxial compressive stress state in the specimen will 270 not be changed if the specimen is not subjected to lateral constrain (either by applying radial 271 confinement pressure or being constrained by interface friction).

272 The influences of both radial confinement pressure and friction coefficient on the 273 compressive strength are affected by the friction angle significantly. It is interesting to note that 274 when the friction angle is zero, radial confinement pressure and interface friction can still 275 influence the compressive strength, but not significantly when compared to the cases with large 276 friction angle. This is because even when the friction angle is zero the D-P model is not exactly 277 the same as the metal plasticity model whose compressive stress-strain curve is not influenced 278 by lateral confinements. For given values of $P$ and $\beta$, dilation parameter $\psi$ has a slight influence 279 on the maximum quasi-static compressive strength for high values of $P$. However, it is shown in 280 Fig. 4 that $\psi$ has considerable influence on the apparent dynamic compressive strength of mortar 281 as indicated by the DIF- $\log (\dot{\varepsilon})$ curves, particularly for strain-rates higher than $1001 / \mathrm{s}$. These 282 results show that numerical modelling results are sensitive to parameters $\mu, \beta$ and $\psi$ in certain 283 regions, and therefore, they should be carefully calibrated in numerical modelling.

284 The effect of friction on the dynamic response of SHPB specimen is well known, which may 285 lead to the over-prediction of DIF [3, 6, 23]. This issue is important for concrete-like sample 286 because its end surface is usually rougher than the surface of a metallic sample [1]. Therefore, 287 friction should not be completely neglected even though lubricant is used. Figure 4 also shows 288 the effect of the friction coefficient $\mu$ on the dynamic strength of mortar for various $\beta$ and $\psi$. It 289 can be seen that when $\beta=\psi=0$, the increase of $\mu$ has some influence on the measured DIF; 290 however when $\beta$ and $\psi$ increase, the DIF increases largely with the increase of $\mu$. This can be 291 explained by the fact that when $\beta$ increases the material becomes more pressure dependant, and 292 therefore, more sensitive to the lateral confinement. Experimental results from Grote et al. [14] 293 are included in Fig. 4 as a reference. The value of the coefficient of friction was not given in 
294 Grote et al. [14] neither it was mentioned if lubricant was used. It is believed that the increase of

295 DIF shown in Grote et al. [14] is only partially due to genuine strain-rate effects.

296

297

298

299

300

301

302

303

304

305

306

307

308

309

310

311

312

313

314

315

316

317

318

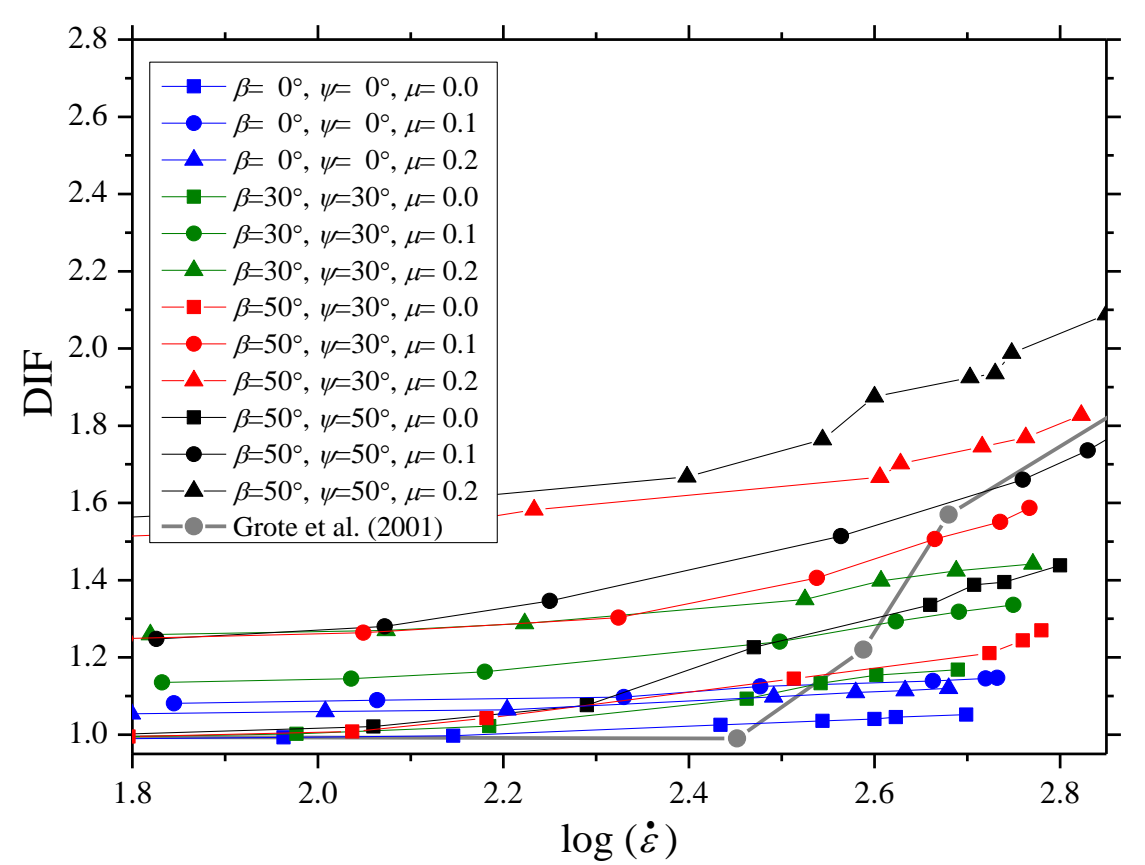

Fig. 4 Numerical results at different strain-rates using various material parameter sets in the D-P model in Abaqus/explicit.

Figure 5 shows the contour plot of radial stress and equivalent plastic strain (PEEQ) for specimens at strain-rate of $\log (\dot{\varepsilon}) \approx 2.7$, for various sets of $\beta, \psi$ and $\mu$. As expected, the lateral confinement, which can be represented by the compressive radial stresses, increases when the interface friction coefficient is increased. It can also be seen that for specimens with same friction coefficient, the lateral confinement increases when the dilation parameter is increased. 


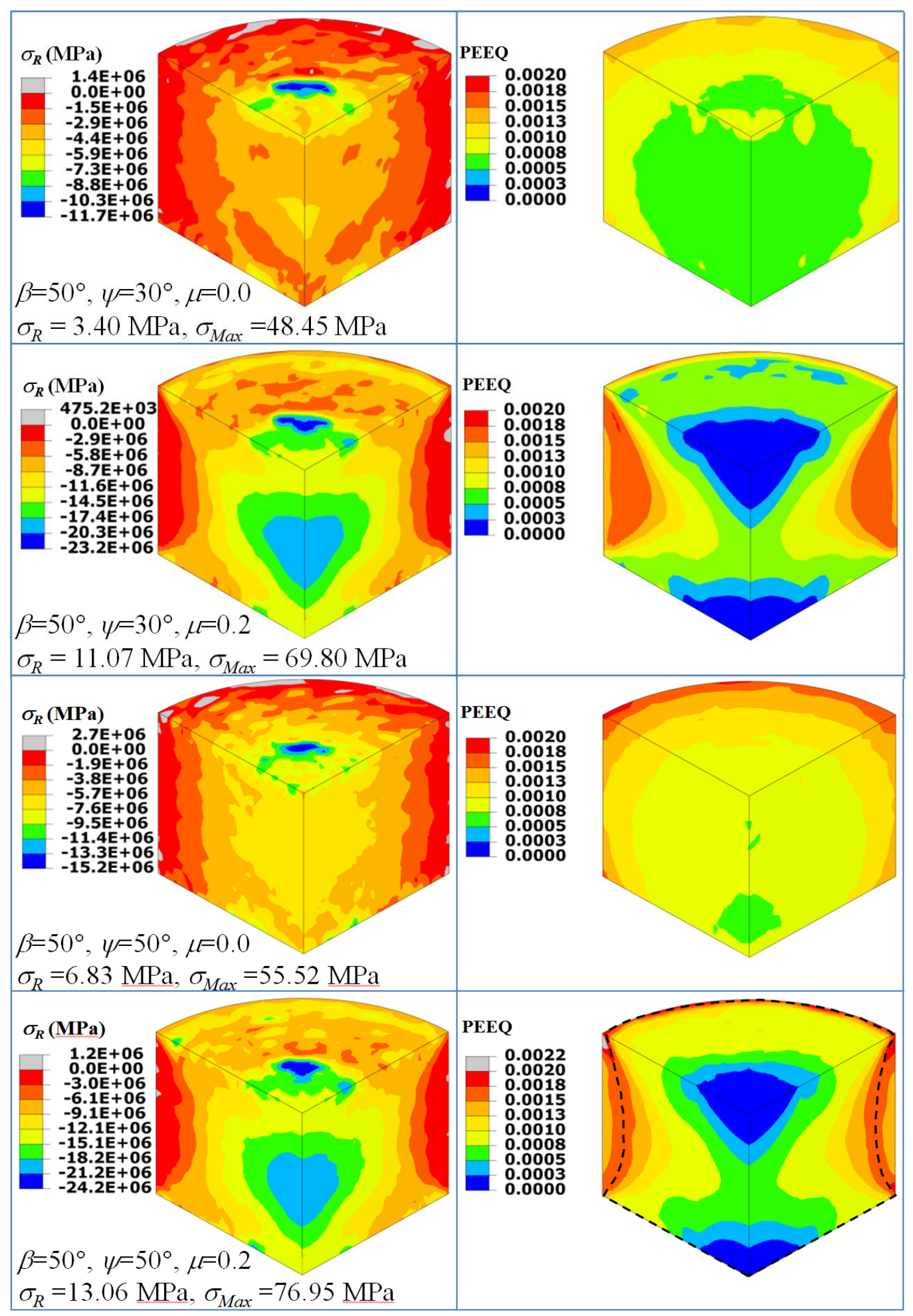

Fig. 5 Contour plots of radial stress and PEEQ for $\log (\dot{\varepsilon}) \approx 2.7$ for various material parameters sets.

It is noted that the dependence of the peak stress on the average radial stress in Fig. 5 is

352 is also observed that PEEQ increases when the dilation parameter is increased. The radial stress

353 (or dynamic confinement) is produced in the hourglass-shaped region [11], which is delimited 
354 by the fault regions with high PEEQ and volumetric expansion or dilation (In Fig. 5, see dashed 355 black line in the PEEQ contour of $\left.\beta=50^{\circ}, \psi=50^{\circ}, \mu=0.2\right)$. This phenomenon has been observed 356 in [11] from numerical simulations using the Material 072R3 model. It is worth to address again 357 the importance of the dilation parameter in the numerical prediction of the compressive strength 358 of the concrete sample, particularly for strain-rates higher than $10^{2} \mathrm{~s}^{-1}$. Therefore, a good 359 calibration of this parameter should be performed to ensure accurate predictions.

360 To understand the inertia effects on the DIF, numerical simulations were carried out using 361 one-tenth and one-hundredth of the material nominal density, i.e., $\rho=200 \mathrm{~kg} / \mathrm{m}^{3}$ and $\rho=20 \mathrm{~kg} / \mathrm{m}^{3}$, 362 respectively. Figure 6 shows a comparison of numerical SHPB tests for three different material 363 densities. It can be seen that when the density is reduced to $\rho=200 \mathrm{~kg} / \mathrm{m}^{3}$, the DIF does not 364 increase with the increase of strain-rate at the same rate as it does for the nominal density $365\left(\rho=2000 \mathrm{~kg} / \mathrm{m}^{3}\right)$ (note: the reduction of material density will increase the stress wave speed and 366 reduce the stress equilibrium time, and thus, will not affect the validity of SHPB test simulation). 367 Since axial inertia affects the additional axial stress only for soft materials, the additional stress 368 due to axial inertia is normally not concerned for solid materials [24, 25]. Thus, the observed 369 inertia effect can only be attributed to the lateral inertia, which generates lateral confinement 370 leading to the increase of DIF. When density is further reduced to $20 \mathrm{~kg} / \mathrm{m}^{3}$, the DIF is almost 371 independent of strain-rate. The correlation between strain-rate and strain acceleration in a SHPB 372 test was noted in [2]. With the increase of strain-rate, axial strain acceleration is also increased, 373 which leads to the increase of lateral confinement as a result of the increase of radial inertia. 374 Therefore, inertia effect is an important mechanism contributing to the structural effects in a 375 SHPB test. However, Fig. 6 also shows the different DIF values obtained for different 376 coefficients of friction when other parameters are the same, which again showed that interface 377 friction is an independent mechanism for structural effect.

378 Previous researches have stated that Poisson's ratio has an effect on the radial inertia in 379 SHPB [26, 27]. In order to investigate this effect, numerical simulations with zero Poisson's 380 ratio were performed and results are shown in Fig. 6. It can be seen that the predictions of DIF 381 when using either $\nu=0$ or $\nu=0.19$ are the same for a friction coefficient $\mu=0$; however, when $382 \mu=0.2$, DIF increases with Poisson's ratio when it varies from $v=0.0$ to $v=0.19$. It transpires that 383 interface friction may restrain the lateral elastic deformation of the sample due to Poisson's 384 effect, which generates lateral confinement and causes the increase of DIF. 


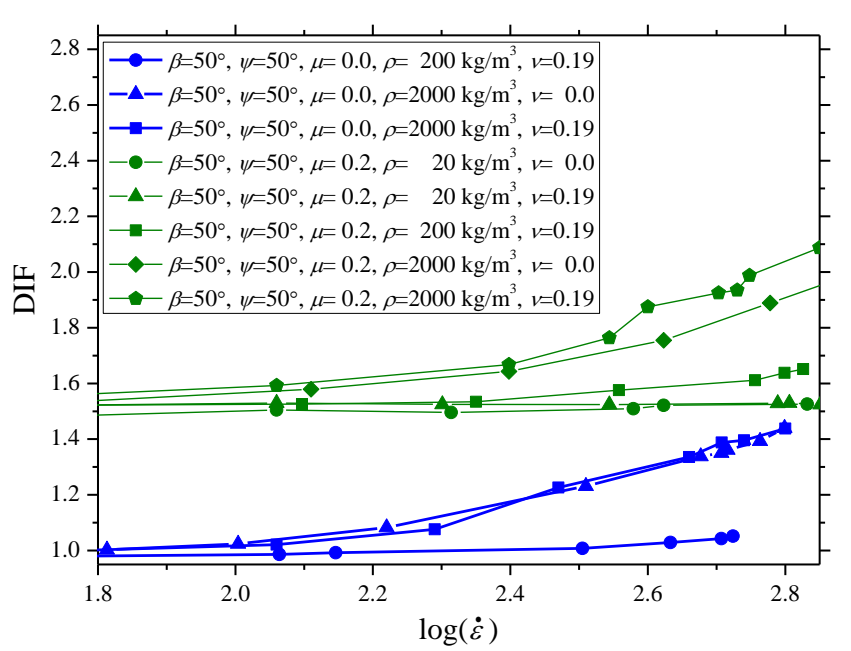

Fig. 6 Finite element model of SHPB test using different material densities and Poisson's ratios.

Figure 7 shows numerical simulations for specimens with diameters of $12 \mathrm{~mm}$ and $20 \mathrm{~mm}$. It can be seen that an increase in the specimen diameter while keeping the same length $(6 \mathrm{~mm})$ leads to an increase of DIF which agrees with previous research [1,2]. Larger sample diameter restricts the lateral deformation through radial inertia and interface friction, and thus, increases the lateral confinement causing the increase of DIF. When the material density is artificially reduced, the influence of specimen diameter on DIF still exists. Therefore, larger specimen diameter promotes the lateral confinement in a dynamic compressive test, leading to the increase of DIF.

Fig. 7 Finite element model of SHPB test using different material densities and friction coefficients for diameters

\subsection{Numerical simulations using Material 072R3 in LS-DYNA}

419 Figure 8 depicts quasi-static compression stress-strain curves at low strain-rate $\left(\dot{\varepsilon}=8 \times 10^{-2} \mathrm{~s}^{-1}\right)$ 420 with different lateral confinement $P$ using Material 072R3 model in LS-DYNA. It can be observed that the dilation parameter $\omega$ does not affect the shape of the softening part of the 
curves for $\omega=(0.0,0.5)$. However, the stress-strain curves degrade at higher rates with the increase of $\omega$. It can also be seen that $\omega$ does not affect the compressive strength of the sample 424 for a given value of $P$.

425 Figure 9 shows the effects of the dilation parameter $\omega$ and the coefficient of friction $\mu$ on DIF using the Material 072R3 model in LS-DYNA. It is observed that when $\mu$ increases the DIF increases as expected due to the increase of lateral confinement. For simulations with the same friction coefficient, DIF increases when $\omega$ increases from 0.5 to 1 ; however, there is no significant effect when $\omega$ increases from 0 to 0.5 . These observations agree generally with Abaqus simulation results.

431 Figure 10 shows contour plots of radial stress and effective plastic strain for specimens subjected to strain-rate of $\log (\dot{\varepsilon}) \approx 2.7$, respectively, for various sets of $\omega$ and $\mu$. Unlike Abaqus,

433 LS-DYNA does not have the option to display results in cylindrical coordinate system, and thus, 434 the radial stress in Fig. 10 is displayed by cutting sections of the specimen using planes parallel 435 to the faces with symmetrical boundary conditions at a distance of $0.05 \mathrm{~mm}$. The stresses in the directions perpendicular to the loading direction represent the radial stress at these cutting planes.

437 Similar to the results observed in Fig. 5, the lateral confinement represented by the radial stress 438 increases when the friction coefficient is increased and/or the dilation parameter is increased. 439 The peak stresses observed in Fig. 10 are somewhat comparable to the quasi-static peak stresses 440 in Fig. 8 due to the lateral confinement $P$. The effective plastic strain also increases when the dilation parameter is increased.

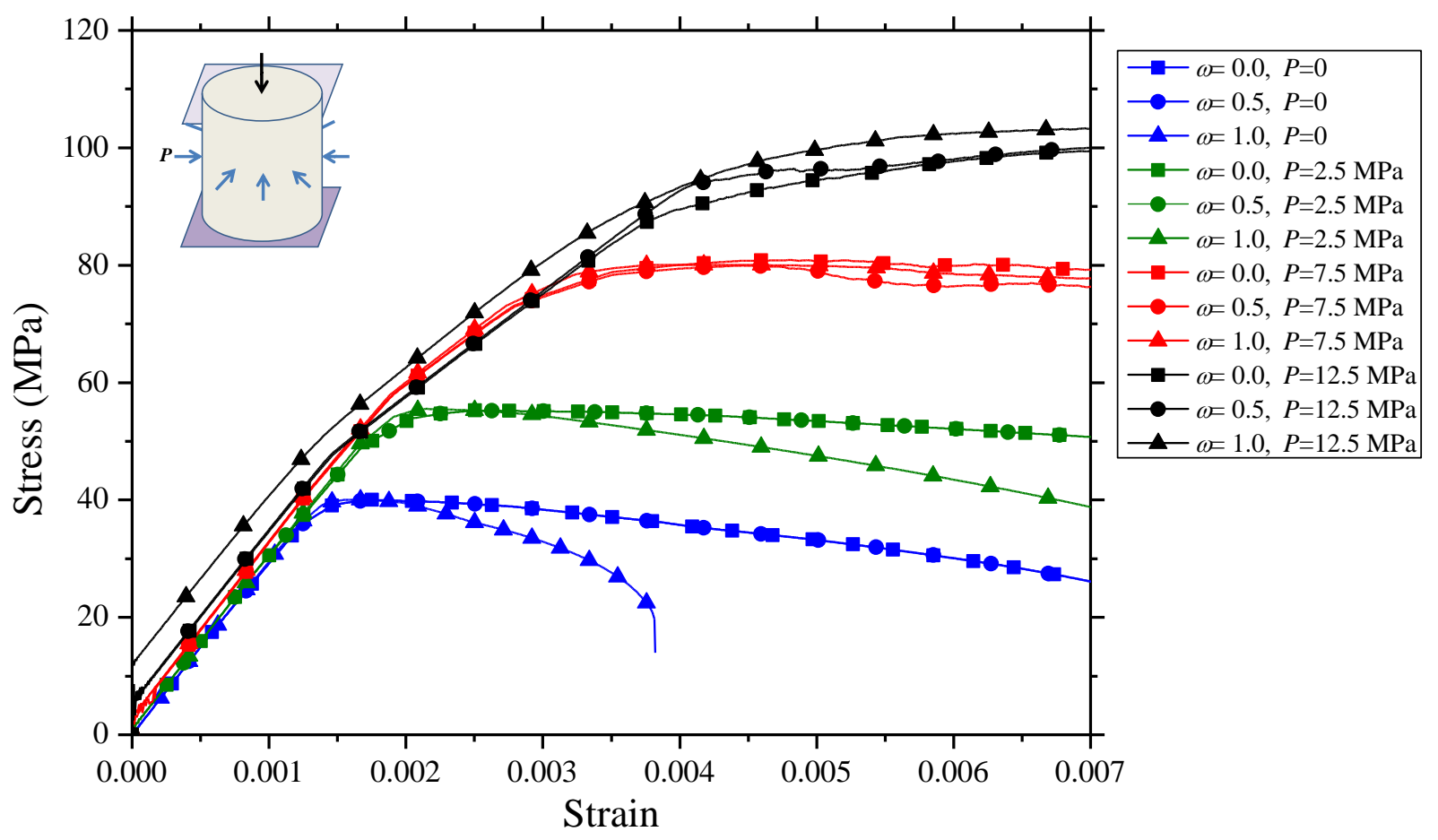


Fig. 8 Stress-strain curves for different input parameters and lateral confinements at $\dot{\varepsilon}=8 \times 10^{-2} \mathrm{~s}^{-1}$ for the Material 458 072R3 model in LS-DYNA using the material properties in Table 1.

459

460

461

462

463

464

465

466

467

468

469

470

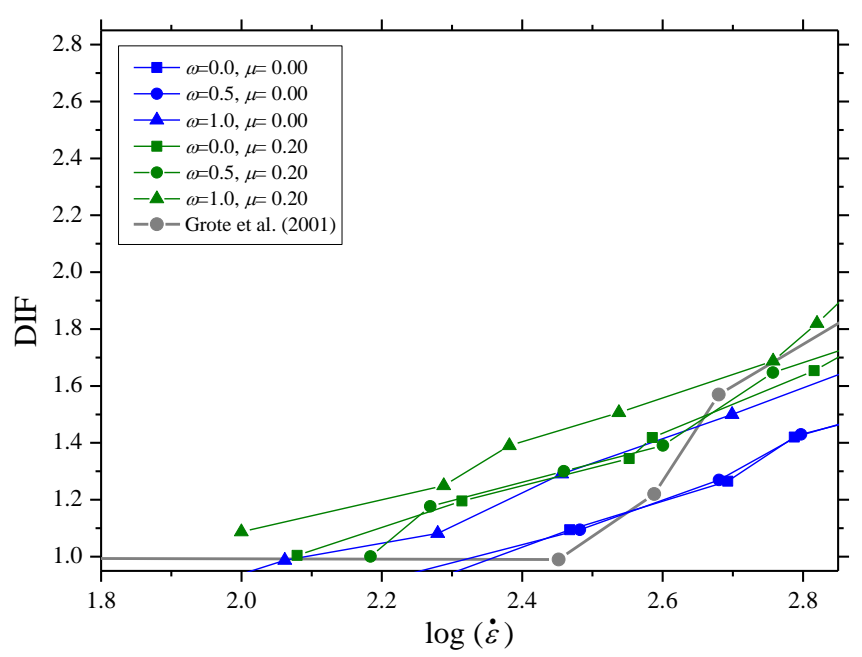

471

472 Fig. 9 Numerical results at different strain-rates using various material parameter sets in the Material 072R3 model 473 in LS-DYNA.

474

475

476

477

478 


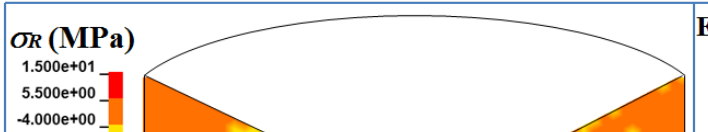

\section{Effective Plastic Strain}

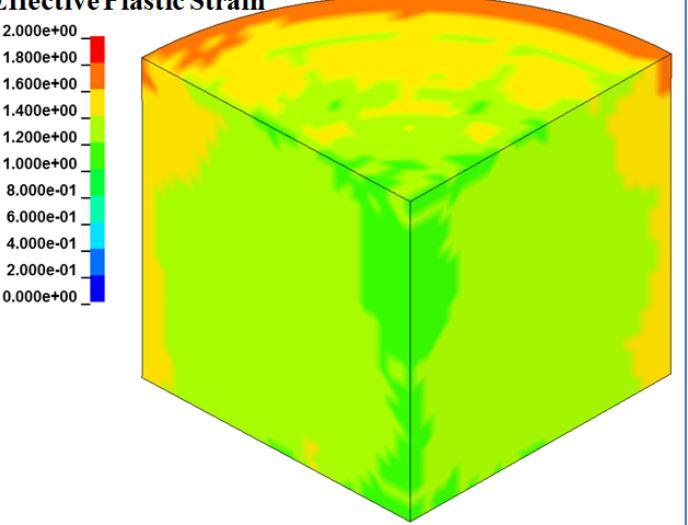

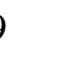

1

3

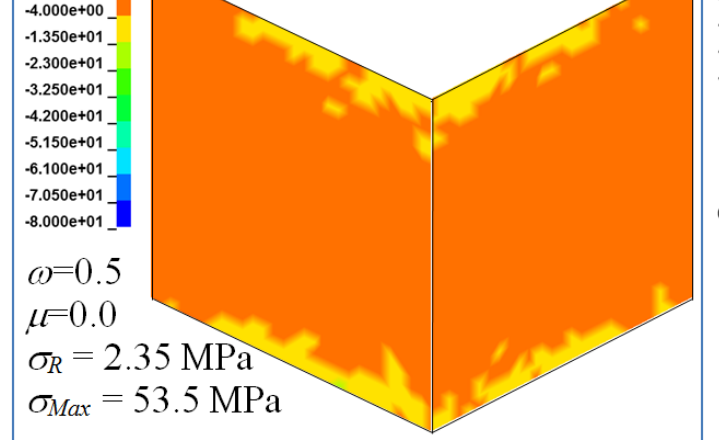

$\left.\begin{array}{l}\hline \sigma_{R}(\mathbf{M P a}) \\ 1.500 \mathrm{e}+01 \\ 5.500 \mathrm{e}+00\end{array}\right]$

\section{Effective Plastic Strain}
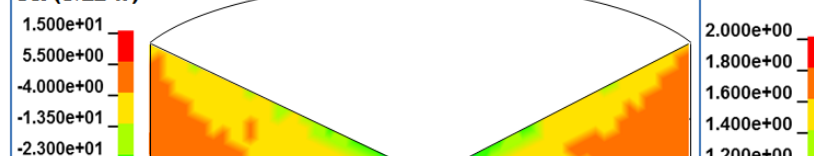

$1.800 \mathrm{e}+00$

$1.600 \mathrm{e}+00$

$1.400 \mathrm{e}+00$

$1.200 \mathrm{e}+00$
$1.000 \mathrm{e}+00$

$-3.250 \mathrm{e}+01$

$-3.200 \mathrm{e}+01$

$-5.150 \mathrm{e}+01$

$-6.100 \mathrm{e}+01$
$-7.050 \mathrm{e}+01$
$-8.000 \mathrm{e}+01$

$-8.000 \mathrm{e}+01$

$\omega=0.5$
$\mu=0.2$

$\sigma_{R}=5.97 \mathrm{MPa}$

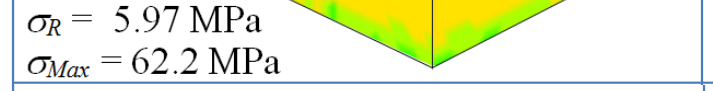

$8.000 \mathrm{e}-01$

6.000e- 01

4.000e-01

$2.000 \mathrm{e}-01$

$0.000 \mathrm{e}+00$
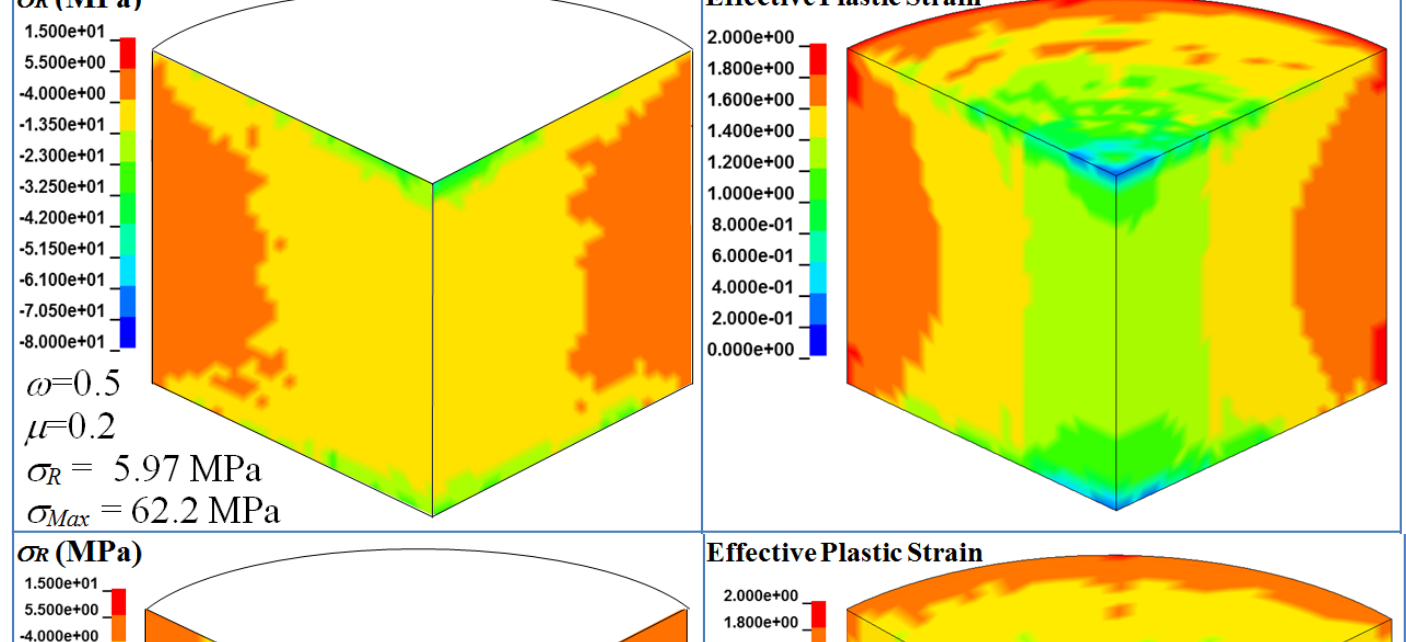

Effective Plastic Strain

\section{$2.000 \mathrm{e}+00$}

$1.800 \mathrm{e}+00]$

$1.600 \mathrm{e}+00$

$1.400 \mathrm{e}+00$
$1.200 \mathrm{e}+00$
$1.000 \mathrm{e}+00$

$8.000 \mathrm{e}-01$
$6.000 \mathrm{e}-01$

6.000e-01

2.000e- 01

$0.000 \mathrm{e}+00]$

$\left.\begin{array}{l}-7.050 \mathrm{e}+01 \\ -8.000 \mathrm{e}+01\end{array}\right]$

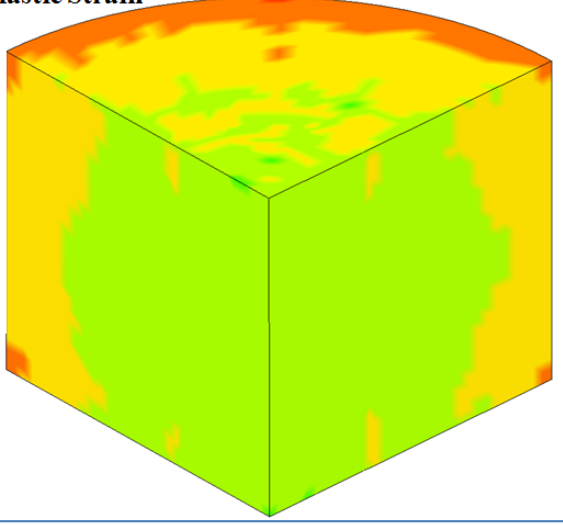

$\sigma_{R}=2.38 \mathrm{MPa}$
$\sigma_{\text {Max }}=54.9 \mathrm{MPa}$

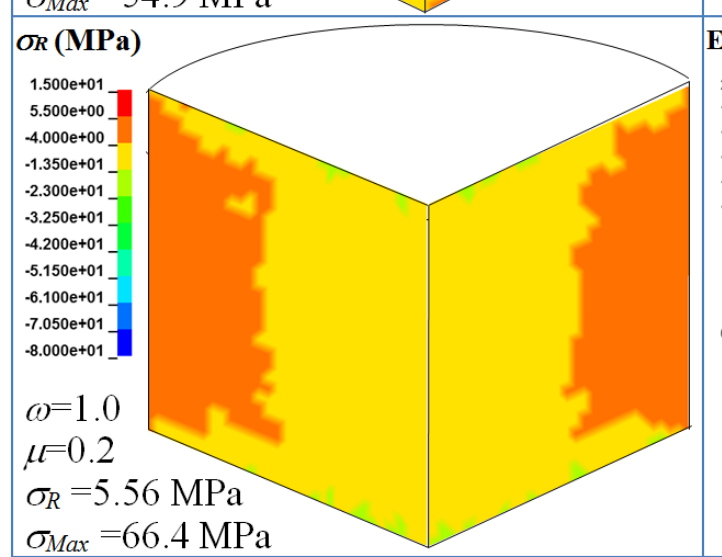

Effective Plastic Strain

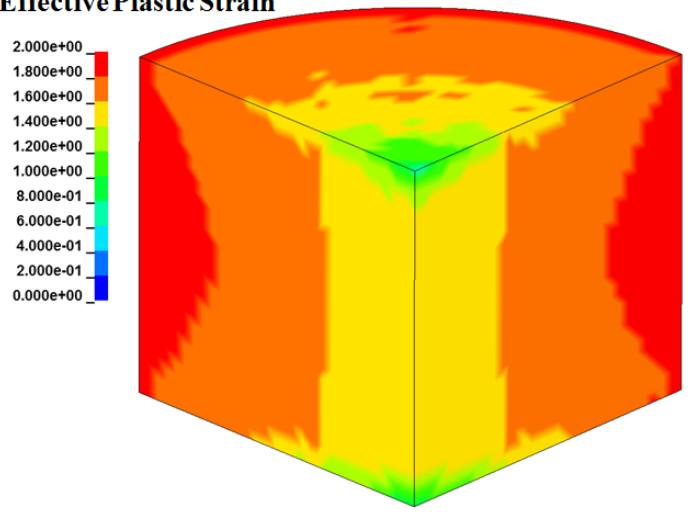

Fig. 10 Contour plots of radial stress and effective strain for $\log (\dot{\varepsilon}) \approx 2.7$ for various material parameters sets. 

on DIF

While it is clear that dilation affects DIF according to the results shown in previous sections and in [11], it remains unclear what mechanisms are responsible for the DIF enhancement through the material dilation. To understand how dilation affects DIF and interacts with other factors, nine cases shown in Table 3 are carefully selected and evaluated. Time histories of compressive stress, radial stress, volume change and plastic strain for each case are shown in Fig. 11 where the normalized time starts from the beginning of the loading in the specimen until the maximum compressive strength is reached. In all cases, $\log (\dot{\varepsilon}) \approx 2.7$ is used.

Table 3 Nine selected cases to demonstrate the effect of dilation and other factors on DIF

\begin{tabular}{|c|c|c|c|c|c|c|c|c|c|}
\hline CASE & A & B & C & D & E & F & G & H & I \\
\hline Friction angle $\beta\left(^{\circ}\right)$ & 0 & 50 & 50 & 50 & 50 & 50 & 50 & 50 & 50 \\
\hline Dilation angle $\psi\left({ }^{\circ}\right)$ & 0 & 50 & 0 & 0 & 50 & 50 & 0 & 0 & 50 \\
\hline Density $\rho\left(\mathrm{kg} / \mathrm{m}^{3}\right)$ & 2000 & 2000 & 20 & 2000 & 20 & 2000 & 2000 & 20 & 20 \\
\hline Poisson's ratio $v$ & 0.19 & 0.19 & 0 & 0 & 0.19 & 0 & 0.19 & 0 & 0.19 \\
\hline$\mu$ & 0.2 & 0 & 0.2 & 0 & 0 & 0 & 0 & 0 & 0.2 \\
\hline$D(\mathrm{~mm})$ & 20 & 20 & 12 & 12 & 20 & 12 & 12 & 20 & 20 \\
\hline DIF & 1.22 & 1.64 & 1.29 & 1.17 & 0.99 & 1.35 & 1.15 & 0.99 & 2.10 \\
\hline
\end{tabular}

For Case A (Fig.11(a)), dilation parameter $\psi$ and friction angle $\beta$ are set to zero to have a hydrostatic independent material. It can be seen, however, that some DIF enhancement $(\mathrm{DIF} \approx 1.22)$ still exists. Similar observation is shown in Fig. 4 for $\psi=\beta=0$ (smaller specimen diameter of $12 \mathrm{~mm}$ is used). This may be due to the flow rule of the D-P model, which creates the multiaxial stress state resulting in some DIF enhancement. For Case B (Fig.11(b)), despite of coefficient of friction being zero $(\mu=0)$, large increase of DIF $(\sim 1.64)$ is observed, which demonstrates that other structural factors (dilation and inertia) can produce DIF enhancement.

540 Case C (Fig.11(c)) demonstrates that for a specimen with $\psi=0$, low density and small diameter, 541 interface friction can independently contribute to structural effects for a hydrostatic-dependent 542 material (DIF=1.29). For Case D with $\mu=0, \psi=0$ and small diameter, an enhancement of DIF 543 ( 1.17) shows that inertia $\left(\rho=2000 \mathrm{~kg} / \mathrm{m}^{3}\right)$ can independently contribute to the structural effect 544 for a hydrostatic-dependent material. For Case E, with low density, no interface friction and 545 large dilation parameter (Fig.11(e)), there is large volume change in the plastic region but the 546 radial stress is very small resulting in negligible DIF enhancement (DIF $\approx 0.99$ ). For Case $\mathrm{F}$ 547 (Fig.11(f)) with no interface friction, DIF 1 1.35, which demonstrates that dilation can enhance 548 inertia effects. For Case G in Fig.11(g) with no dilation effect and no interface friction, DIF 549 enhancement is marginal $(\mathrm{DIF} \approx 1.15)$ when $v=0.2$, which can be compared to Case $\mathrm{D}$ with the 
exactly same parameters except $v=0$. This shows that Poisson's ratio has little structural effect on DIF enhancement when there is no dilation effect or interface friction (See Fig. 6); however, results in Fig. 6 for large dilation and large interface friction show that Poisson's ratio has some small influence on DIF. A comparison of Fig. 11(d) with Fig. 11(g) shows that the reduction of volume before peak strength is larger in Case D $(v=0)$ than in Case $\mathrm{G}(v=0.19)$. This suggests that the increase of Poisson's ratio may enhance DIF through dilation or interface friction by facilitating lateral expansion of the specimen. For Case H (Fig.11(h)) with $\mu=0, \psi=0$, large diameter and low density, there is no DIF enhancement $(\mathrm{DIF} \approx 0.99)$. This shows that the material inertia (density) is necessary for the DIF enhancement in a SHPB specimen with large diameter. Finally for Case I (Fig.11(i)) with large diameter, dilation and interface friction, DIF is enhanced significantly $(\mathrm{DIF}=2.10)$. This large enhancement suggests that despite of low density, dilation can also enhance DIF through interface friction when Case I is compared with Case E. This indicates that dilation can enhance DIF through either inertia or friction, or both of them. This means that radial expansion alone (without radial inertia due to material density or radial confinement due to friction) results in no DIF enhancement in a material that is sensitive to hydrostatic pressure. This point can be further illustrated if we focus on Cases B, E, F, I with large dilation parameter $\psi$. For these cases, there is large volumetric change in the plastic regime when compared to the rest of the cases (Fig. 11). The material expansion leads to the increase of the radial stress when density is large (Case B, F) or interface friction is large (Case I), which in turn produces lateral confinement that results in an increase of DIF.

When the strain-rate is high enough $(\log (\dot{\varepsilon})>2)$, there is a correlation between the axial strain-rate and the axial strain acceleration [2]. The accelerated axial motion produces an accelerated radial motion leading to an inertia-induced radial confinement. When the strain-rate is below the transition strain-rate, axial acceleration is significantly small. This can be seen in

574 Fig.12 (a) in which the axial acceleration is compared for some of the cases in Table 3. Two extra cases similar to Case B (i.e. Case B with $\log (\dot{\varepsilon}) \approx 2$ and Case B with $\psi=30^{\circ}$ ) are also included in Fig. 12. It can be seen that the axial acceleration for Case B with $\log (\dot{\varepsilon}) \approx 2$ is much smaller than those in other cases in Fig. 12 with higher strain-rate, and its corresponding DIF is marginal ( 1.04). It can also be seen in Fig. 12 (a), that the axial acceleration is somewhat similar in all cases in which $\log (\dot{\varepsilon}) \approx 2.7$. This supports the experimental finding in [2] that axial acceleration is correlated with strain-rate. By comparing Case B (large density, DIF enhancement) with Case E (low density, no DIF enhancement), which have similar axial accelerations, it can be seen that the axial acceleration can only enhance DIF through material 583 inertia. 
584 (a)

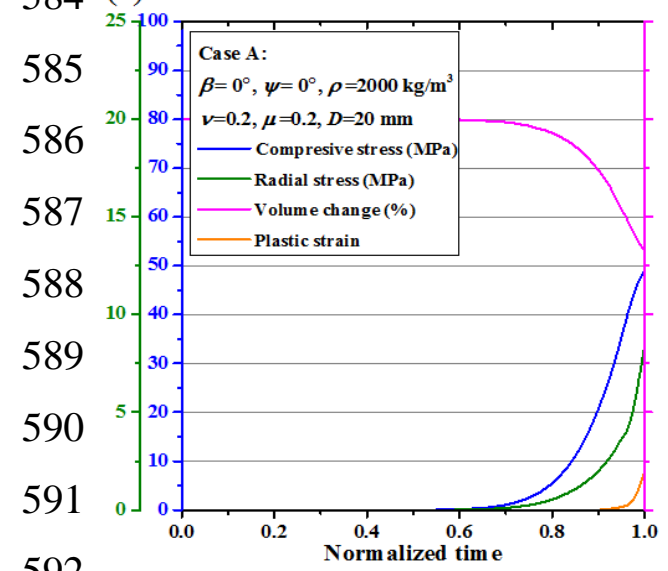

592

(d)

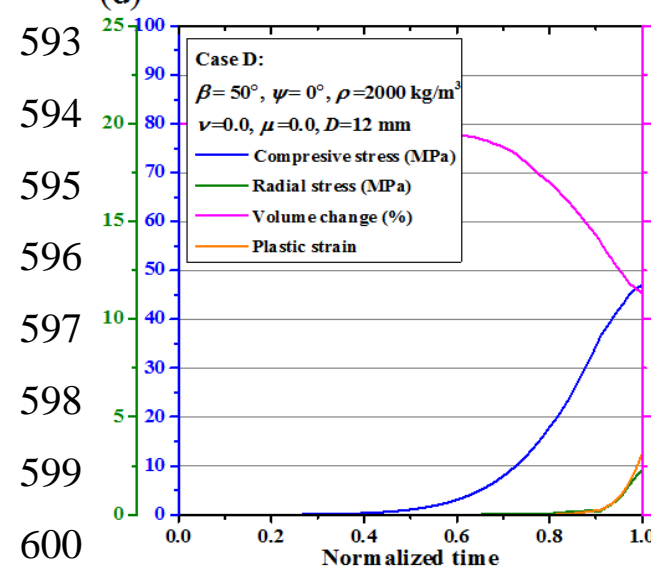

600

601 (g)

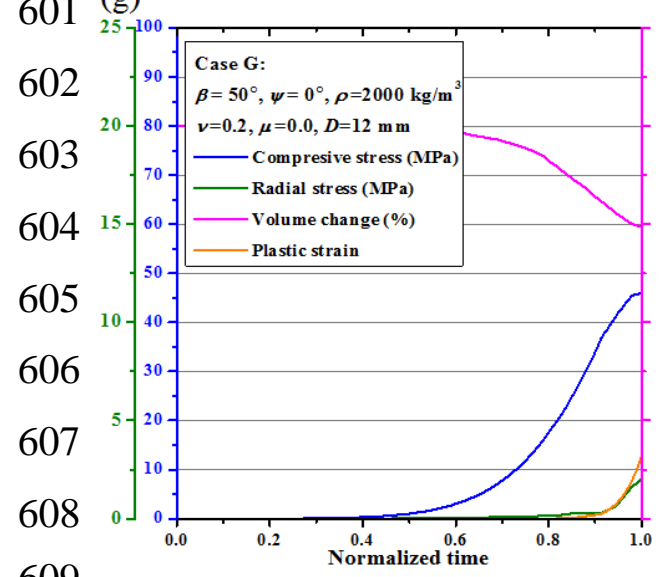

(b)

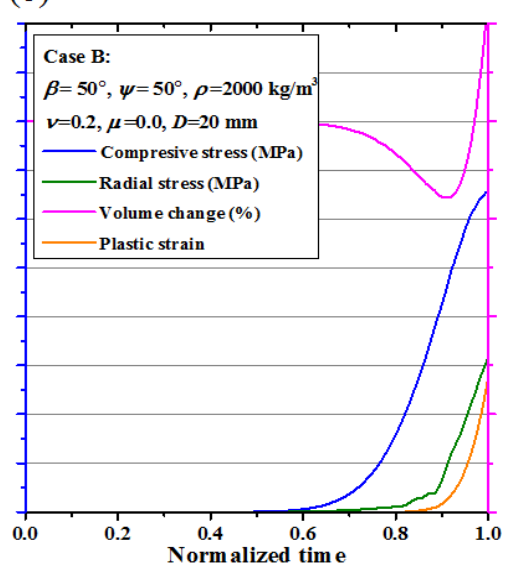

(e)

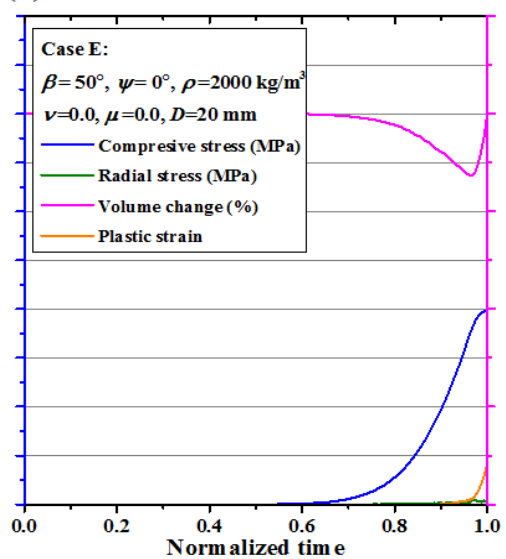

(h)

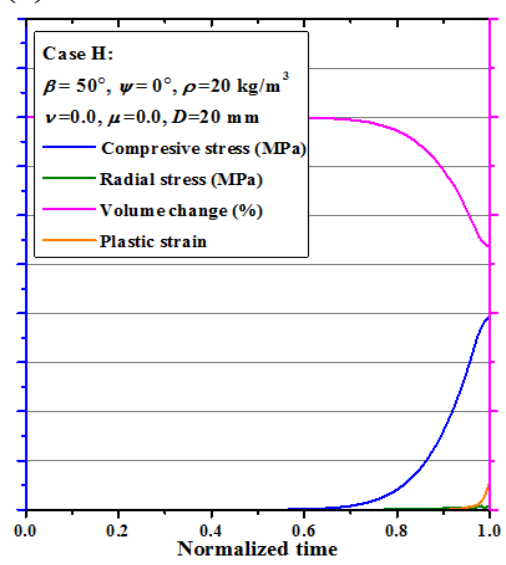

(c)

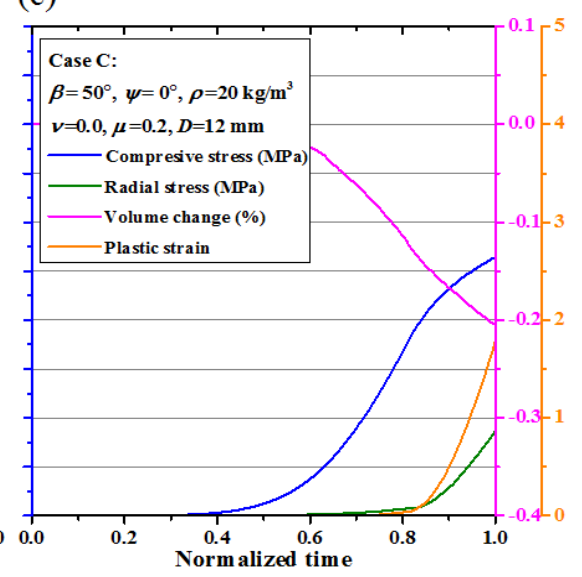

(f)

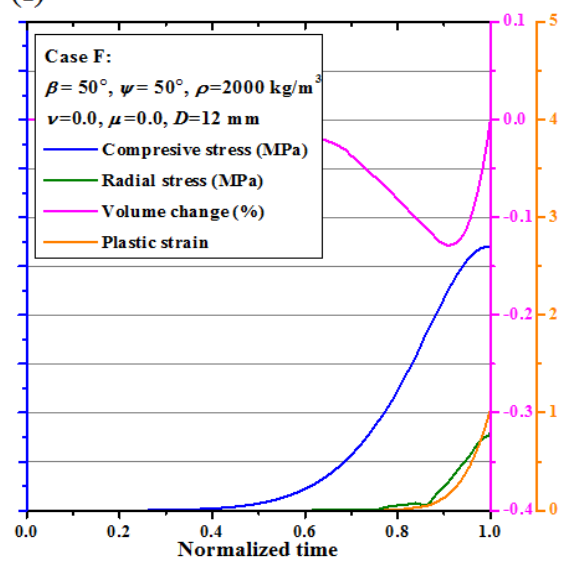

(i)

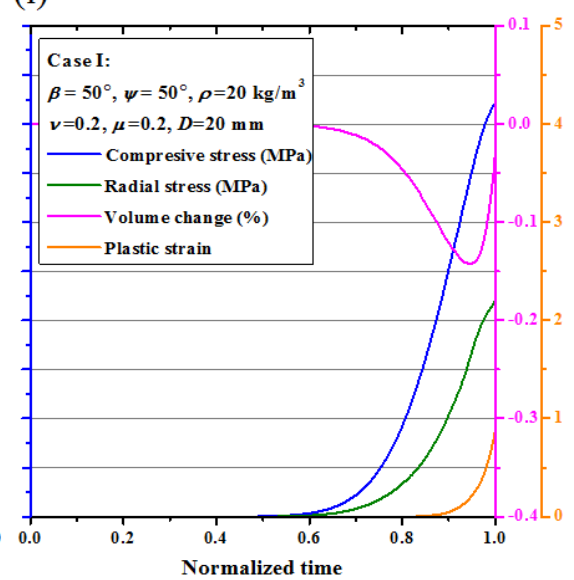

610 Fig. 11 Time histories of compressive stress, radial stress, volume change and plastic strain for 9 different loading 611 cases (Cases A-I in Table 3) using D-P model in Abaqus.

612

613

614

615 
Figure 12 (b) shows the time history of the plastic Poisson's ratio (ppr), defined as the ratio between lateral strain and axial strain, for the same cases shown in Fig. 12 (a). It can be seen

618 that $p p r$ increases with the increase of dilation. For Case B with $\psi=30^{\circ}, \mathrm{DIF}=1.42$. This DIF 619 enhancement is smaller than that of Case B with $\psi=50^{\circ}(\mathrm{DIF}=1.64)$. This shows that the 620 reduction of dilation results in a reduction of $p p r$ and this in turn results in less DIF 621 enhancement. Since $p p r$ affects the relationship between axial and radial motion, large $p p r$ 622 enhances the radial motion and the lateral expansion. Thus, it plays similar roles as Poisson's ratio in elastic regime. With inertia, the lateral expansion will cause lateral confinement. Inertia starts to play its role when strain-rate is larger than a critical value.

625

626

627

628

629

630

631

632

633

634

635

636

637

638

639

640

641

642

643

644

645

646

647

648

649

650

651 (a)

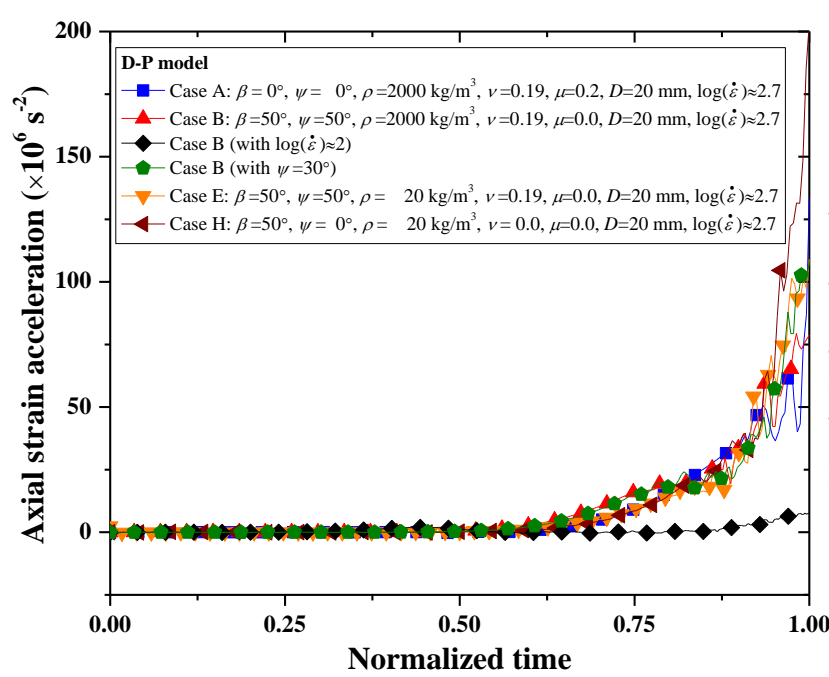

(b)

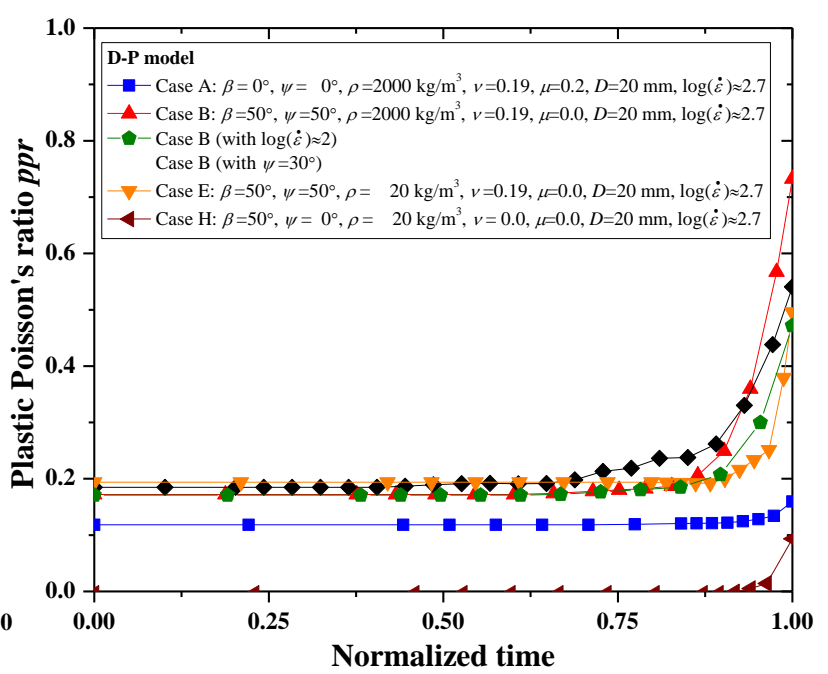

Fig.12 Time histories of (a) axial acceleration and (b) plastic Poisson's ratio (ppr) for different loading cases (Table 3) using D-P model in Abaqus

Based on the above analyses of the numerical results, a flow chart (Fig. 13) is constructed to show the interactive mechanisms that produce structural parameters that influence DIF. DIF can be enhanced by structural effects for hydrostatic-dependent materials when lateral confinement is introduced due to structurally-produced radial stresses. The two main mechanisms that can produce lateral confinement are interface friction and radial inertia. These two mechanisms can either individually or collaboratively exist to produce lateral confinement. Other structural factors (e.g. Poisson's ratio, dilation and specimen diameter) can further enhance DIF, but they have to interact with either or both mechanisms. Finally, large axial acceleration, which is correlated with strain rate in SHPB test, is necessary for the radial acceleration to generate radial inertia in a SHPB specimen. 


\section{Mechanism I:}

Interface friction represented directly by the coefficient of friction $(\mu)$

663

Mechanism-II:
radial inertia represented

666 directly by material

667

668

669

670 Radial acceleration

671 produced

$672 i$ by axial acceleration due to material flow rule (including Poisson's ratio effect and dilation) density $(\rho)$
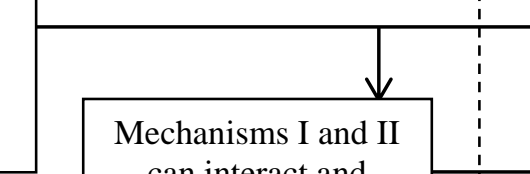
can interact and
Lateral confinement (radial stress) is produced collaboratively produce lateral confinement

\section{Conclusions and Remarks}

The numerical study conducted in this paper shows that the increase of the apparent dynamic increase factor (DIF) with strain-rate in concrete-like materials in a SHPB test is a complex phenomenon related not only to material strain-rate effects but also to structural effects. Strainrate independent material model is employed in this study in order to isolate the structural effects for a hydrostatic-dependent material. It is found that two mechanisms can produce lateral confinement, i.e. interface friction and radial inertia, which can enhance DIF individually or collaboratively for hydrostatic-dependent materials. Dilation, Poisson's ratio (or material flow rule in a more general sense) and specimen diameter can further enhance DIF, but they have to interact with either or both lateral confinement mechanisms. It was also found that radial inertia (radial acceleration) starts to enhance DIF when strain-rate reaches a critical strain-rate (transition strain-rate) in the order of $10^{2} \mathrm{~s}^{-1}$. The correlation between axial strain acceleration and strain-rate observed numerically in the present study supports the reported experimental observation. However, there is still a lack of explanation for the existence of such correlation.

693 Although, the existence of genuine strain-rate effects have been suggested by meso-scale 
694 simulations and micro-crack models [28-30], the findings in this study show that structural

695 effects have a significant contribution to the measured DIF, and therefore, one needs to be 696 cautious about interpreting SHPB data for concrete-like materials. Otherwise, the material 697 model with considering strain-rate effect based directly on SHPB measurement may over698 predict material strength and lead to non-conservative design and assessment of protective 699 structures.

Acknowledgement: The second author acknowledges the support from National Natural

Science Foundation of China (11272060).

\section{Appendix}

\section{A.1 Extended Drucker-Prager constitutive model in Abaqus}

$F=t-p \tan \beta-d=0$

where $\beta$ is the friction angle of the material, which is the slope of the linear yield surface in the

$712 d=\sigma_{c}\left(1-\frac{1}{3} \tan \beta\right)$

713 where $\sigma_{c}$ is the unconfined uniaxial compressive yield stress. The deviatoric stress measure $t$ is 714 defined as,

where $q=\sqrt{\frac{3}{2} \mathbf{S}: \mathbf{S}}=\sqrt{3 J_{2}}$ is the Mises equivalent stress; $r$ is the third invariant of the deviatoric 719 stress given by $r=\left(\frac{9}{2} \mathbf{S} \cdot \mathbf{S}: \mathbf{S}\right)^{1 / 3}=3\left(\frac{1}{2} J_{3}\right)^{1 / 3}$ where $\mathbf{S}$ is the deviatoric stress defined as $720 \boldsymbol{S}=\boldsymbol{\sigma}+p \mathbf{I}$, being $\boldsymbol{\sigma}$ and $p=-\frac{1}{3}\left(\sigma_{11}+\sigma_{22}+\sigma_{33}\right)=-\frac{1}{3} I_{1}$ the stress tensor and equivalent 721 pressure stress, respectively. The first invariant of the stress tensor and the second and third 722 invariants of the deviatoric stress tensor are $I_{1}, J_{2}, J_{3}$, respectively. The parameter $K$ is the ratio 723 of the yield stress in triaxial tension to the yield stress in triaxial compression [15]; $K$ has to be 724 within the range $0.788 \leq K \leq 1$ to ensure the convexity of the yield surface. The flow rule of the 725 D-P model is given by [18], 
$d \boldsymbol{\varepsilon}^{p}=\frac{d \varepsilon^{p}}{c} \frac{\partial G}{\partial \sigma}$

where $\varepsilon^{p}$ is the equivalent plastic strain; $c$ is a constant given by $(1-1 / 3 \tan \psi)$ if hardening is defined in uniaxial compression, which is the concern of the present study. The plastic flow potential $G$ is defined as,

$G=t-p \tan \psi$

where $\psi$ is the dilation angle. If $\psi=0$, the plastic deformation is incompressible (a nonassociative flow rule) and when $\psi>0$ the material dilates (Fig. A1(a)). When $\psi=\beta$ and $K=1$, a fully-associative flow rule is obtained and the original Drucker-Prager model is reinstated [15]. It can be seen in Fig. A1(a) that $\psi=\theta-\theta_{n}$, in which $\theta$ varies from $\theta_{n}$ to $\theta_{n}+\beta$ (i.e. $0 \leq \psi \leq \beta$ ). For concrete-like materials, it has been found that $\psi$ and $\beta$ are in the ranges of $20-50^{\circ}$ and $20-60^{\circ}$, respectively [31-33]. When the hardening is defined in uniaxial compression, the flow rule precludes dilation angles $\psi>71.5^{\circ}$ (or $\tan \psi>3$ ). It is unnecessary to discuss this restriction since it unlikely occurs for the studied materials in this paper [15].

a)

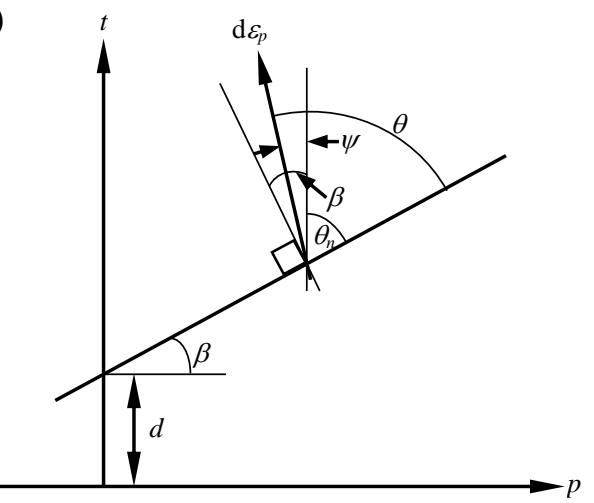

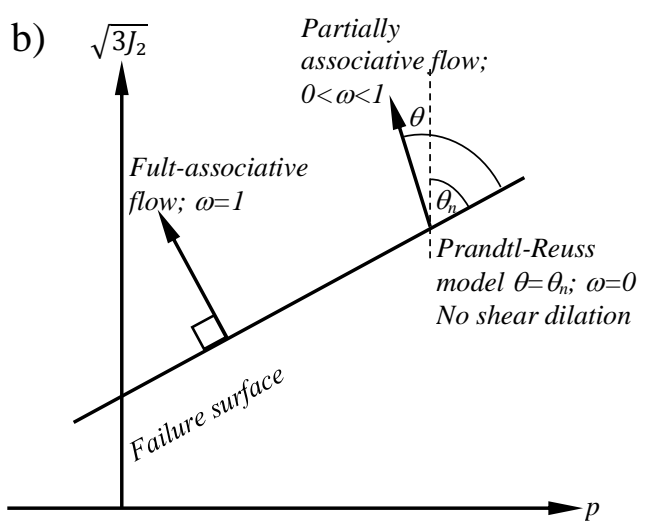

753

Fig. A1 Yield surface and flow direction in (a) D-P model in Abaqus [15]; (b) Material 072R3 model in LS-DYNA 754 [12].

\section{A.2 Concrete Damage Model Release III (Material 072R3) in LS-DYNA}

Material 072R3 implemented in LS-DYNA was employed to study the effect of dilation on SHPB testing of concrete. The model has linear behaviour until the yield stress point is reached. The plastic response of the material is predicted via three independent strength surfaces, i.e., the

760 yield failure surface $\Delta \sigma_{y}$, the maximum failure surface $\Delta \sigma_{m}$ and the residual failure surface 
$763 \Delta \sigma_{m}=a_{0}+\frac{p}{a_{1}+a_{2} p}$

$764 \Delta \sigma_{r}=\frac{p}{a_{1 f}+a_{2 f} p}$

765 where $a_{0 y}, a_{1 y}, a_{2 y}, a_{0}, a_{1}, a_{2}, a_{1 f}, a_{2 f}$ are user-defined parameters that control the shape of

766 the strength surfaces. The loading surfaces, $\Delta \sigma_{L}$ representing strain hardening after yield and the 767 post-failure surfaces $\Delta \sigma_{p f}$ representing strain softening after maximum strength, are defined as 768 [19],

$\Delta \sigma_{L}\left(I_{1}, J_{2}, J_{3}\right)=r\left(J_{3}\right)\left[\eta(\lambda)\left(\Delta \sigma_{m}(p)-\Delta \sigma_{y}(p)\right)+\Delta \sigma_{y}(p)\right]$

where $\eta(\lambda)$ is a function of the internal damage parameter $\lambda$ and is calibrated experimentally; $r\left(J_{3}\right)$ is a scale factor in the form of William-Warnke equation $[19,34]$, which introduces the dependence of $J_{3}$ in order to properly model material behaviour under confinement [19].

$g=\sqrt{3 J_{2}}-\omega F\left(I_{1}, J_{2}, J_{3}\right)$

where $F$ is defined as the loading surfaces in Eqs.(A7a, A7b). The plastic flow rule is given by an expression of the plastic strain increment $d \varepsilon_{i j}^{p}$ as [35],

where $\sigma_{i j}$ is the stress tensor and $d \tilde{\mu}$ is the plasticity consistency parameter [35, 36]. Dilation is taken into account by the Material 072R3 via the parameter $\omega$, which defines the amount of dilation that can occur in the material. When $\omega=1$, a fully-associative flow rule applies, i.e., plastic flow develops along the normal to the yield surface. When $\omega=0$, there is no volume change during plastic flow (Fig. A1(b)), which is a non-associative flow rule, e.g. Prandtl-Reuss 
$\omega$ values for concrete have been found to be between 0.5 and 0.7 [12], which indicates that

partially-associative flow rule is used.

\section{References}

1. Li, Q.M., Lu, Y.B., Meng, H. Further investigation on the dynamic compressive strength enhancement of concrete-like materials based on split Hopkinson pressure bar tests. Part

II: Numerical simulations. Int. J. Impact Eng. 2009;36:1335-1345.

2. Zhang, M., Wu, H.J., Li, Q.M., Huang, F.L. Further investigation on the dynamic compressive strength enhancement of concrete-like materials based on split Hopkinson pressure bar tests. Part I: Experiments. Int. J. Impact Eng. 2009;36:1327-1334.

3. Kim, D.J., Sirijaroonchai, K., El-Tawil, S., Naaman, A.E. Numerical simulation of the Split Hopkinson Pressure Bar test technique for concrete under compression. Int. J. Impact Eng. 2010;37:141-149.

4. Mu, Z.C., Dancygier, A.N., Zhang, W., Yankelevsky, D.Z. Revisiting the dynamic compressive behavior of concrete-like materials. Int. J. Impact Eng. 2012;49:91-102.

5. Li, Q.M., Meng, H. About the dynamic strength enhancement of concrete-like materials in a split Hopkinson pressure bar test. Int. J. Solids Struct. 2003;40:343-360.

6. Meng, H., Li, Q.M. Correlation between the accuracy of a SHPB test and the stress

uniformity based on numerical experiments. Int. J. Impact Eng. 2003;28:537-555.

7. Bertholf, L.D., Karnes, C.H. Two-dimensional analysis of the split hopkinson pressure bar system. J. Mech. Phys. Solids 1975;23:1-19.

8. Hao, Y., Hao, H., Jiang, G.P., Zhou, Y. Experimental confirmation of some factors influencing dynamic concrete compressive strengths in high-speed impact tests. Cem. Concr. Res. 2013;52:63-70.

9. Hao, Y., Hao, H. Numerical Investigation of the Dynamic Compressive Behaviour of Rock Materials at High Strain Rate. Rock Mech. Rock Eng. 2013;46:373-388.

10. Cusatis, G. Strain-rate effects on concrete behavior. Int. J. Impact Eng. 2011;38:162-170.

11. Elmer VII, W., Taciroglu, E., McMichael, L. Dynamic strength increase of plain concrete from high strain rate plasticity with shear dilation. Int. J. Impact Eng. 2012;45:1-15.

12. Noble, C., Kokko, E., Darnell, I., Dunn, T., Hagler, L., Leininger, L., Concrete model descriptions and summary of benchmark studies for blast effects simulations. 2005, Lawrence Livermore National Laboratory (LLNL), Livermore, CA, USA.

13. Bischoff, P., Perry, S. Compressive behaviour of concrete at high strain rates. Mater. Struct. 1991;24:425-450.

14. Grote, D.L., Park, S.W., Zhou, M. Dynamic behavior of concrete at high strain rates and pressures: I. experimental characterization. Int. J. Impact Eng. 2001;25:869-886.

15. Simulia, Abaqus Analysis User's Manual (Version 6.11). 2011, SIMULIA.

16. Hallquist, J.O., LS-DYNA Keyword User's Manual, Version 971. 2007, Livermore Software Technology Corporation: California.

17. Schwer, L.E., Malvar, L.J., Simplified concrete modeling with *MAT_CONCRETE_DAMAGE_REL3, in 4rd German LS-DYNA Forum '05. 2005: Bamberg, Germany.

18. Simulia, Abaqus Theory Manual (Version 6.11). 2011, SIMULIA.

19. Wu, Y., Crawford, J.E., Magallanes, J.M., Performance of LS-DYNA ${ }^{\circledR}$ concrete constitutive models, in 12th International LS-DYNA ${ }^{\circledR}$ Users Conference. 2012: Detroit, USA.

20. Lu, Y.B., Li, Q.M. Appraisal of Pulse-Shaping Technique in Split Hopkinson Pressure Bar Tests for Brittle Materials. Int. J. Protective Struct. 2010;1:363-390. 
21. Ravichandran, G., Subhash, G. Critical appraisal of limiting strain rates for compression testing of ceramics in a split Hopkinson pressure bar. J. Am. Ceram. Soc. 1994;77:263267.

22. Song, B., Chen, W. Split Hopkinson pressure bar techniques for characterizing soft materials. Lat. Am. J. Solids Struct. 2005;2:113-152.

23. Hartley, R.S., Cloete, T.J., Nurick, G.N. An experimental assessment of friction effects in the split Hopkinson pressure bar using the ring compression test. Int. J. Impact Eng. 2007;34:1705-1728.

24. Song, B., Ge, Y., Chen, W.W., Weerasooriya, T. Radial Inertia Effects in Kolsky Bar Testing of Extra-soft Specimens. Exp. Mech. 2007;47:659-670.

25. Zhang, M., Li, Q.M., Huang, F.L., Wu, H.J., Lu, Y.B. Inertia-induced radial confinement in an elastic tubular specimen subjected to axial strain acceleration. Int. J. Impact Eng. 2010;37:459-464.

26. Kolsky, H. An Investigation of the Mechanical Properties of Materials at very High Rates of Loading. 1949;62:676-700.

27. Forrestal, M.J., Wright, T.W., Chen, W. The effect of radial inertia on brittle samples during the split Hopkinson pressure bar test. Int. J. Impact Eng. 2007;34:405-411.

28. Snozzi, L., Caballero, A., Molinari, J.F. Influence of the meso-structure in dynamic fracture simulation of concrete under tensile loading. Cem. Concr. Res. 2011;41:11301142.

29. Qin, C., Zhang, C. Numerical study of dynamic behavior of concrete by meso-scale particle element modeling. Int. J. Impact Eng. 2011;38:1011-1021.

30. Song, Z., Lu, Y. Mesoscopic analysis of concrete under excessively high strain rate compression and implications on interpretation of test data. Int. J. Impact Eng. 2012;46:41-55.

31. Park, S.W., Xia, Q., Zhou, M. Dynamic behavior of concrete at high strain rates and pressures: II. numerical simulation. Int. J. Impact Eng. 2001;25:887-910.

32. Jiang, J.-F., Wu, Y.-F. Identification of material parameters for Drucker-Prager plasticity model for FRP confined circular concrete columns. Int. J. Solids Struc. 2012;49:445-456.

33. Luccioni, B.M., Luege, M. Concrete pavement slab under blast loads. Int. J. Impact Eng. 2006;32:1248-1266.

34. Malvar, L.J., Crawford, J.E., Wesevich, J.W., Simons, D. A plasticity concrete material model for DYNA3D. Int. J. Impact Eng. 1997;19:847-873.

35. Crawford, J.E., Wu, Y., Choi, H.-J., Magallanes, J.M., Lan, S., Use and validation of the Release III K\&C Concrete Material Model in LS-DYNA. 2012, Karagozian \& Case, Glendale, CA, USA.

36. Wu, Y., Crawford, J.E. Numerical Modeling of Concrete Using a Partially Associative Plasticity Model. J. Eng. Mech. 2015;141:04015051. 